\title{
Potential of Multi-Agent Systems for Operation of Transportation Systems
}

Janusz Madejski

Politechnika Śląska, Wydział Mechaniczny Technologiczny, Instytut Materiałów Inżynierskich i Biomedycznych, ul. Konarskiego 18a, 44-100 Gliwice

\begin{abstract}
The article discusses the possibility of implementation of the currently available solutions with software agents in transport, focusing on applications for planning transport systems, control, monitoring and analysis of the state of the superstructure and potential applications to the planning of the maintenance tasks.
\end{abstract}

Keywords: software agents, multi-agent systems, simulation, planning, inspection WUINU

\section{Introduction}

Transportation systems are composed of a multitude of interrelated entities which may be assigned to many various classes (means of transportation, passengers, elements of the permanent way, maintenance tasks and many others). All of them interact with a dynamically changing environment. Controlling such systems has been done, to date, by human staff. However, more and more often, automation replaces humans with their experience, knowledge, ability to react to the unexpected events - yet also being prone to getting tired, sleepy, ill, intoxicated, to mention only but a few of their weak points.

Agent-based systems are particularly suited to take over tasks like decentralized decision making, monitoring, localglobal interactions, self-organization, emergence and consequences of heterogeneity in their environment.

An agent's complexity can range from a simple sensing agent that reacts to its environment only but has no memory and no model of other agents, all the way up to full human capabilities. Actual implementations add at least memory to sensing capability, making it possible to the agent to maintain its local state. The next level of sophistication is self-consciousness, in which each agent knows of the existence of other agents distinct from itself, and thus can carry on simple communication. A social agent goes a step further and models other agents' states, goals, and plans. Even higher capabilities include such functions as making commitments to one another, planning tasks and learning from experience. In industry, more complex functions are usually provided by using artificial agents as an interface for a human operator, to whom they furnish information and from whom they take commands.

The real life heterogeneous environment is composed of agents which may be either humans or software agents. In

\section{Autor korespondujący:}

lanusz Madejski, janusz.madejski@polsl.pl

\section{Artykuł recenzowany}

nadesłany 11.01.2016 r., przyjęty do druku 19.02.2016 r. some cases the software agent may represent a physical object, e.g., a passenger deciding whether to take a bus or go by car or else a locomotive scheduled for maintenance which intervenes with the maintenance centre to have its overhaul date and scope confirmed. Agent systems may be used either in the transportation system design, to decide its topology and types of connections, and for running the real life systems, in which human and software agents carry out their tasks fully interacting with each other.

Many contemporary industrial or business applications, designed as centralized software systems are not as efficient as distributed societies of relatively simpler software agents. For example, to compete effectively in today's rapidly changing environment, companies must be able to design, implement, reconfigure, resize, and maintain their resources without delay and inexpensively.

As mentioned above, the multi-agent systems may consist of both human and software agents. Therefore, solving the communication problem between these two types of agents is the key issue. Nowadays, such interactions are still a weak point as regards the scope of topics and vocabulary involved. Even in the case of tasks which may be delegated either to a human agent or the software one, e.g., checking the completeness of the railway car suspension overhaul, humans still outshine their eventual software counterparts.

Therefore, the more efficient human - software agent communication would let the software agents ask humans for advice. This way, the software agents may be simpler, easier to develop and debug, which would make them more reliable. Thanks to such approach, even a small human intervention may completely change the way the software agent deals with its problem, enabling the software agent or an automated system to cope with the situation too complicated for it. In the predictable environment, like metro systems, the driverless trains have appeared long ago - London Underground's Victoria line was opened in 1967 yet with the driver in the cab, taking care of door closing, obstacle detection in front of the train and handling the emergency situations. In a stateof-the-art system like the Barcelona Metro line 10 (Grade of Automation 4), trains are capable of operating automatically, and the on-board staff are not required for safe operation [17].

Such human support or backup has made the development of the self-driving cars and mot probably they will be intro- 
duced to the consumer market by 2020. Google's self-driving cars have now driven nearly two million miles with only 11 minor accidents, most of them caused by human error, while making 10,000-15,000 autonomous miles per week on public streets [6]. The self-driving cars may significantly reduce the number of cars on the road. Singapore's Land Transportation Authority predicted that fleets of self-driving cars could reduce the number of cars on the road by around 80 percent [13]. Introduction of the mass transit systems is considered, composed of two layers:

- network of big vehicles, like trains or buses for the long-distance trips,

- and the fleet of the self-driving cars for short, individually requested rides or picking passengers from hubs $[1,4]$.

We will discuss below agents which may be either simple devices for acquiring huge amounts of data, software agents, multi-agent systems and the issue of humans - agents cooperation.

\section{Agent Systems}

Development of any agents requires adopting their behavioral structure. Agents can be described as having the following characteristics $[3,5,15]$ :

- Perception: the agent perceives the environment and is aware of presence of other agents in the vicinity;

- Performance: the agent has a set of behaviors and can act accordingly communicating with other agents and performing actions;

- Memory: the agents have memory with results of actions and former states;

- Rules: the agents must have a set of rules (designed by their developers or generated automatically), heuristics and strategies, determining their behaviors which may be dependent on their past actions and their characteristics.

Development of the relevant systems calls for collecting the experience gathered to date in the system operated by human 'agents'. Such knowledge base may be used to replicate the behavior of the system controlled by such operators. The event-oriented fuzzy models developed that way, represent single agents which - when needed - should be able to solve problems jointly, should they exceed the capacity of a single agent. Therefore, negotiation skills are needed which lead either to a delegation of a task to a single agent or to setting up an ad-hoc task group to handle the problem.

\subsection{Agent Behavior}

The key features of the agents' behavior which can range from simple rules to, e.g., neural networks, genetic programming, and other AI methods [12, 14-16]:

- Modularity: the agent must be easily identifiable;

- Autonomy: an agent should be autonomous and self-directed, should work independently of the environment and have behaviors influenced by their perceptions also by information obtained through interaction with other agents;

- State: the agent has a state that varies with time and represents the main variables associated with the temporary situation;

- Sociability: the agent is social, with dynamic interaction between the other agents being capable of influencing their behavior and recognizing and distinguish their features;

- Adaptivity: the agent should have rules or mechanisms modifying their behavior. Such approach may lead to selection of the fittest and elimination of less useful agents;
- Goal: the agent can seek goals, compare results and modify their behaviors in the future.

While the agents programmed by humans have behavioral rules and algorithms programmed by a researcher, independent agents are governed by rules generated by computers, bringing results of greater magnitude and often unexpected $[1-3,14]$.

As an ideal, we would like to build our models around agents whose rationality is limited in the same way that human rationality and whose decision-making behavior to replicate or move closer to the behavior human decision making.

Meeting the real-time reaction requirement calls for a twolevel approach. The need to reach a solution in real time does not allow lengthy deliberation process which calls for pre-compiled procedures and contingency plans to be carried out whenever required. There are two different approaches to agent design, depending on their types. There are the physical and functional decomposition approaches. The physical decomposition is used for development of agents, representing the physical entities, like workers, machine tools, tools, fixtures, or products, etc. The functional decomposition approach is used when agents are assigned to some functions, like product distribution, transport management, order acquisition, scheduling, material handling, etc. Development of the multi-agent systems requires taking into account the particular features of the two above mentioned approaches.

Each agent is close to the real world, so the overall system behavior is controlled by local decisions, the system reacts to environmental noise, removal or addition of agents. The software for each agent is much shorter and simpler than would be required for a centralised approach and resultingly is easier to write, debug, and maintain.

The main point of the MAS is to augment, rather than replace, the human operator. In some cases, humans function as peer agents, rather than just as operators. That is, other agents do not distinguish between interactions with humans and interactions with artificial agents.

Computer-supported collaborative work (CSCW) uses computer technology to integrate communities of humans and adding artificial agents. Either artificial agents can be made so intelligent that people come to view them as peers, or people can be represented in the network by artificial agents that make them look to other agents like computers.

\subsection{Multi-Agent System (MAS) Design Principles}

Transportation systems are composed of a big number of objects. Therefore, development of the multi-agent systems should ensure implementation of the following principles $[5,9,11]$, to name but a few:

- Functional heterogeneity: the agent architecture must respect the heterogeneity of capabilities found in the physical system with which they have to interact, be they stochastic or deterministic processes;

- Interaction: the agent architecture must be capable of carrying out agent to agent communication;

- Scope of physical agents: the agents' scope and boundaries should be aligned with their corresponding physical resources if any;

- Temporal scope of execution agent: the characteristic frequencies in the physical system model must be controlled by a dedicated execution agent which has to be able to make decisions much faster than the fastest characteristic frequency;

- Temporal scope of coordination agent: a dedicated coordination agent may not take decisions faster than about an 
order of magnitude slower than the slowest characteristic frequency in the physical system model - to maintain the system stability.

The programming model required for simulation of the agent based systems may take various forms. The most direct way is to use a programming language, object-oriented generally, such Java, C++ or Visual Basic. One can also use libraries like Swarm, Repast, Mason or NetLogo [1, 2].

\section{Applications}

\subsection{Traffic Planning and Monitoring}

The study of the demand for transport is a multidisciplinary field of study that it involves sectors of the social sciences as well as of engineering. Urban mobility is a recurring theme in political discussions and often it is included among the greatest challenges of urban planning. Application of computational agent-based models may help to circumvent the constant inefficiency of the traditional approach to the study of this problem. Planning of transport infrastructure calls for determining how it would be used, depending on prices and operational policies.

A simple approach might use agents having, e.g., two choices, either car or bus, and two departure times. The test results of a multi-agent model showed convergence to equilibrium after a few rounds of interaction [1]. Such model may, therefore, identify how, from the variables chosen, the consumer decides between one or the other alternative trip. The modelling of the decisions associated with transportation is not limited to the choice between either modal (car or bus for example) but may include a variety choices. Among the other choices traditionally found in the literature are the choice of whether or not to make the trip, where and when to travel and which route to take.

The aim of the simulation-based agents is to enrich understanding of important processes that repeatedly appear in social studies, and not necessarily seeks to obtain an accurate representation of some empirical evidence.

Assessing whether a project is feasible, it is necessary to have a measure of benefits it produces. Such estimates are best made by modelling the planned transport system as the multi-agent system. All passengers, vehicles, are represented by agents while nodes of the connection graph refer to the particular bus/metro stops/stations which may have varying importance depending on points of interest in the vicinity. As for the demand study, three objectives of transport planning have to be satisfied $[1,3,12]$ :

- Fine adjustment of taxes and tariffs of urban transport, like toll, bus fare, parking, etc. within budget constraints, and also to maximize the social benefit;

- Estimation of the benefits of alternative designs of urban transport;

- Simulation of the urban economy and prediction of the future transportation needs.

Such analysis, possible with a simulation of the MAS representing the planned transportation system should take into account such features like transportation means' frequency, destination, travel time or ticket price, and also or its consumers description (e.g., sex, income, preferences). The total transportation demand in a city can be related to its geographical features (e.g., as a proportion of hilly areas, rivers), the amount of industry and households, the average cost of bus fare, costs alternative models of transport, quality of service.
The modeling of the decisions associated with transportation is not limited to the choice of the possible transportation means (car or bus for example) but may also include a variety of choices. These include whether or not to make the trip, where and when one would travel and which route to take. The choice can take into account possession or not of a private vehicle, place of residence, place of work, or parking locations.

\subsection{Traffic Control}

The continuous increase o the number of vehicles resulting in the significant growth of the traffic flows volume results in economic losses caused by the traffic congestions. In consequence, urban road traffic management has become an increasingly important task. Therefore, strategies to guide traffic flows are essential to avoid losses for the local economy. For a variety of reasons, qualitatively new situation emerges in urban areas, encompassing:

- Huge volume of unstructured data arriving continuously within short time periods that has to be processed, in most cases, in real time.

- The number and complexity of control devices that can be acted upon increases constantly, some of their types are mentioned below.

- The number of simultaneous traffic problems increases while the time frame for working out the signalling features changes is getting shorter.

The tasks which could be delegated to software agents include processing of the continuous and voluminous stream of data coming from a number of sources. The same pertains to taking decisions regarding traffic control and generating messages for drivers. Some possible examples include:

- Routine control of certain problematic areas using TV cameras. They are especially useful to assess automatically any unusual and emergency situations.

- Sensors are installed in strategic parts of the transportation network and generate a continuous flow of numerical data about traffic conditions at a certain point. There are different types of sensors with different costs and capabilities. One of the classical sensors type is a loop detector that usually provides information about speed (mean velocity of the vehicles detected by the sensor), flow (average number of vehicles that pass through a certain road section per time unit) and occupancy (the average duration when the vehicles are spotted by the sensor).

- Variable message signs (VMS) - VMS allow influencing traffic behavior by dynamically setting, modifying or deleting traffic signals. The most advanced VMS are panels that are installed on the road allow displaying arbitrary messages that inform drivers about the network situation downstream. In addition to this, they can show pictograms and traffic signs, thereby announcing warnings, speed limits, prohibitions to overtake, etc. Older types of VMS support just a small collection of different traffic signs or constrain the set of messages that can be displayed due to technical limitations.

- Traffic lights control access of vehicles to certain parts of a road network, especially to road crossings. The traffic light signaling features can be controlled: e.g., the relative amount of green time may be increased or decreased, the overall length of a cycle can be changed. Traffic lights that may be positioned on the entry ramps of highways enable the traffic controller to regulate the amount of vehicles entering the highway. These decisions can be taken by agents and advised to the drivers. 


\section{Permanent Way Condition Monitoring}

Standard inspections of the main railway lines in the main tracks, in good condition of the superstructure and substructure, should be carried out not less than twice a week and of the others once a week. The track inspection for the visual control of the infrastructure elements - no more than $16 \mathrm{~km}$ - should be performed, with few exceptions, during the statutory nominal work time.

In the case of tracks, one must pay attention to the permanent way defects and track deformations. It should be observed in particular that there are no broken rails or fish plates if welds have no visible damages (scratches, cracks). Also, one should check that there is no dangerous development of a defect in the areas marked during the NDT examination, scheduled for observation and whether the condition of rails fixing elements are not missing and are in good condition.

The mentioned requirements arising out of the relevant provisions result that the inspection is very labor intensive and can be carried out only with the good visibility.

It is for this reason that in recent years more and more railway infrastructure operators decide to implement the state-of-the-art video inspection systems. This is due mainly to the increasing railway or metro infrastructure load and, therefore, to the significant deterioration of the safety of staff on tracks and carrying out their standard inspections. Another important reason is the striving to reduce the infrastructure maintenance cost.

The video systems inspection allow to record the infrastructure condition during the passage of a train and then to carry out inspections of the track in the office. Such an approach is equivalent to the standard inspections, except that the train can record data at high speeds, without disturbing the typical traffic of trains and without affecting the railway line safety systems. Collecting the results by the inspection train and subsequent image processing in the office makes the inspection much more efficient and eliminates the need to maintain a significant amount of staff in the infrastructure.

Most of the inspection data, be it track and turnout geometry readings, and video inspection information can be analysed automatically by the dedicated agents. The goal is to focus the diagnostic engineers' attention on the detected problems, relieving them from the tedious task of sifting through voluminous data. Examples of problems that may be detected by such agents include, among others:

- Exceedings of values of the track and turnout geometrical parameters;

- Potentially hazardous occurrences of apparently unharmful values of parameters, yet which together may reduce safety of operation;

- Determining locations in the track network where its geometrical parameters deterioration trend is either bigger than in other similar locations, or has just begun growing;

- Generation of reviews of staff annotations to track defects made during the selected period, e.g., last shift;

- Image processing to detect problems with rail fixtures, e.g., missing elements;

- Image processing to detect rail head defects.

Sometimes one may use agents being the hardware/software units providing useful diagnostic data. A good example is the Macminder system that makes the unattended monitoring possible of vehicle ride performance and track conditions on board of the in-service trains, eliminating the need for track possession [7]. Special annotation overlays and reporting procedures can be applied to provide instantaneous results. This way a number of units carried on board of the in-service vehicles provide automatically valuable diagnostic data which can be analysed by the diagnostic software agents continuously browsing the diagnostic results database.

\section{Planning of Permanent Way Maintenance and Repairs}

Development of the agents for each of the tasks/devices begins with understanding the requirements regarding the permanent way maintenance and repair tasks. This can be done by interviewing the operators to understand what aspects were important to carry out their jobs and control the quality. Working out a list of requirements with their importance ranks makes it possible to come up with the proposed solutions. Only now assigning functionality to planned agents in the system is possible. The next step is to modify the behaviors of the agents so that the overall behavior of the whole system would be as desired. At the early stage of adoption of the agent-based systems, it is recommended that they do not control any devices directly, but recommend certain actions to the human operator. Such approach minimises the risk of possible damage to the equipment and should be taken because of the general safety concerns.

Let us limit our considerations to maintenance and repairs of the permanent way only here. The standard maintenance static scheduling may solve the problem and provide the suboptimal schedule, yet the impractical one, because of the mostly unrealistic assumptions. This is because the real systems are complex and dynamic with a big number of events and processes, with many organisational levels, and subject to random disturbances [8]. One may name some of these disturbances like new orders which may come based on permanent way inspection on a previous night, those queued already may be cancelled; some jobs may become more or less important with time, according to the dynamic priority rules. Moreover, some resources may temporarily become unavailable as deliveries may be delayed, raw materials may be depleted, tools may not be available for some reasons, to name but a few of them: staff may be absent, equipment service life may be reduced due to poor quality or misuse, and many others.

Therefore, the real-time control is needed, as all decisions have to be made based on the current state of the available resources. The artificial software agents may take over the maintenance process scheduling which consists of allocating and timing the manufacturing system resources to complete the queued jobs within the timeframe allowed using the desired criteria $[10]$.

\section{Conclusions}

Nowadays, the greatest challenges faced by any potential user of the multi-agent technologies are mostly social and organizational, and not technical. The main issues include:

- Dramatic changes of the role and importance of staff carrying out scheduling and working with the Management Information Systems. Staff in these areas may treat the new technology as a direct threat to their jobs unless their reservations are discussed openly.

- Machine operators tend to treat their equipment as tools rather than 'partners'. Direct cooperation with agents may require careful implementation planning of such work organization, taking into account customs of the staff.

- The problem of responsibility of the agent malfunctioning should be analyzed, as usually the programmer is to blame, 
yet in certain systems, he or she may not be aware what rules would be generated by the system, controlling the agents' behaviors. This problem may become even more complex in multi-agent systems which negotiate independently which one would accept the tasks, and how it would sometimes be done with a group of agents, in many cases created ad-hoc at some location.

- One should bear in mind that adoption of agents may not yield systems reliable enough in many areas, which will require their close supervision and analysis - maybe by other agents.

- Implementation of the agents always calls for combining them with the legacy control systems to eliminate the need for extra expenditures and development of hardware and communication network.

- Creating and maintaining agent systems easier benefits significantly from the introduction of an agent framework and development environment.

The technology to develop and implement the agent- based systems is available to-date, meeting all requirements - from traffic planning, through its control, diagnostics, and maintenance. The issue remains how this technology, potentially reducing the number of jobs will be perceived by the society.

\section{Bibliography}

1. Avancini D.P., da Silveira J.J., Demanda por transporte rodoviário urbano: um modelo computacional baseado em agentes, Paper published at Universidade Federal de Santa Catarina, Centro Sócio-Econômico, Departamento de Ciencias Econômicas, Florianópolis, 2013, [http://www.anpec.org.br/sul/2013/submissao/ files_I/i3-89c87c96b985313f1e62eb2ef25625f3.pdf].

2. Axelrod R., Advancing the art of simulation in the social sciences. "Journal of the Japanese Society for Management Information Systems", Vol. 12, December 2005 [http://www-personal.umich.edu/ axe/research/ AdvancingArtofSim.pdf].

3. Bandini S., Manzoni S., Vizzari G., Agent Based Modeling and Simulation: An Informatics Perspective. "Journal of Artificial Societies and Social Simulation", 12(4)4, 2009, [http://jasss.soc.surrey.ac.uk/12/4/4.html].

4. Brynjolfsson E., McAfe A., Will Humans Go the Way of Horses?, "Foreign Afairs", July/August 2015, 8-14.

5. Farid A.M., Designing Multi-agent Systems for Resilient Engineering Systems, $7^{\text {th }}$ International Conference,
HoloMAS 2015 Valencia, Spain, September 2-3, 2015, [in:] Marik V., Schirrmann A., Trentesaux D., Vrba P. (Eds.) Industrial Applications of Holonic and Multi-Agent Systems, Proceedings, Springer, 2015, 3-10.

6. Google Self-Driving Car Project, Monthly Report September 2015, [https://static.googleusercontent.com/ media/www.google.com/en//selfdrivingcar/files/reports/ report-0915.pdf].

7. Macminder - Donfabs \& Consillia Limited, [http://www. trackgeometry.co.uk/vehicle_monitoring.htm].

8. Madejski J., Dynamic scheduling for agent based manufacturing systems, Proceedings of the $15^{\text {th }}$ International Scientific Conference AMME 2010, GliwiceZakopane, June 2010.

9. Madejski J., Persistent Agents Behaviour in Diverse Situations, AMME 2013, Kraków, June 2013, Ed. by L.A. Dobrzański. Gliwice: International OCSCO World Press, 2013, 126-127.

10. Marik V., Vrba P., Hall K.H., Maturana F., Rockwell Automation Agents for Manufacturing, Proceedings of AAMAS $05-4^{\text {th }}$ International Joint Conference on Autonomous Agents and Multiagent Systems, Utrecht University, 25-29 July, 2005, 107-113.

11. Müller J., The Design of Intelligent Agents, Springer, 1996.

12. Ossowski S., Coordination in Artificial Agent Societies Structure and Its Implications for Autonomous ProblemSolving Agents, Springer, 1999.

13. Rus D., The Robots Are Coming, "Foreign Affairs", July/ August 2015, 2-7.

14. Shu-Heng Chen, Varieties of agents in agentbased computational economics: A historical and an interdisciplinary perspective, Elsevier, "Journal of Economic Dynamics and Control", Vol. 36. Issue 1. January 2012, 1-25.

15. Tecuci G., Building Intelligent Agents, Academic Press, San Diego, 1998.

16. Telles do Carmo B.B., Eddine M.J., Bandeira de Melo $\mathrm{P}$., The collaboration strategy to improve the quality of a public transportation system: an application using the agent-based simulation with Netlogo, Proceedings of ANPET $-28^{\text {th }}$ Congresso de Pesquisa e Ensino em Transportes, Curitiba (Brazil) 24-28 November 2014.

17. [https://en.wikipedia.org/wiki/List_of_automated_ urban_metro_subway_systems].

\title{
Potencjał systemów wieloagentowych w zastosowaniu do eksploatacii systemu transportowego
}

\author{
Streszczenie: W artykule omówiono możliwość zastosowania dostępnych obecnie rozwiązań \\ $z$ agentami programowymi w transporcie, koncentrując się na zastosowaniach do planowania \\ systemów transportowych, sterowania nimi, monitorowania i analizy stanu nawierzchni kolejowej, \\ a także możliwymi zastosowaniami do planowania prac utrzymaniowych.
}




\section{Janusz Madejski, PhD}

janusz.madejski@polsl.pl

Graduated in 1974 at the Silesian University of Technology in Gliwice - majoring in Machine Tools, Tools and Machine Engineering; Doctor of Engineering - expert in Automation and Robotisation of Industrial Processes, Silesian Technology University, Gliwice, 1982. Assistant Professor at the Faculty of Mechanical Engineering, Silesian Technology University, Gliwice; Director of Engineering and Technology at CRAW -

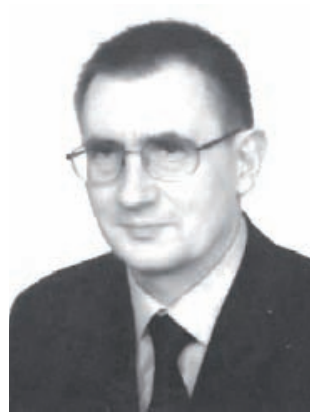
Laser Measurement Systems Sp. z 0.0., Gli-

wice; Freelance translator; Member of the International Academic Scientific Committee of CETRA conferences, Croatia. Member of the Institute of Electrical and Electronics Engineers, Polish Association of Mechanical Engineers and Technicians (Certified Expert, Vice-President of the Science and Technical Board 1986-1989, Silver award 1988), Polish Association of Translators (President of the Silesian Branch board 1999-2005), Kuwait Society of Engineers. Author of 10 patents and utility models; author of 140 publications. 